\title{
Limibacter armeniacum gen. nov., sp. nov., a novel representative of the family 'Flammeovirgaceae' isolated from marine sediment
}

Correspondence

Jaewoo Yoon

aa57058@mail.ecc.u-tokyo.ac.jp

\author{
Jaewoo Yoon, ${ }^{1}$ Yoshihide Matsuo, ${ }^{2}$ Hiroaki Kasai ${ }^{2}$ and Akira Yokota ${ }^{1}$ \\ ${ }^{1}$ Institute of Molecular and Cellular Biosciences, The University of Tokyo, 1-1-1 Yayoi, Bunkyo-Ku, \\ Tokyo 113-0032, Japan \\ ${ }^{2}$ Marine Biotechnology Institute Co. Ltd, 3-75-1, Heita, Kamaishi, Iwate 026-0001, Japan
}

\begin{abstract}
Two strictly aerobic, Gram-negative, gliding, apricot- to pale-orange-pigmented, rod-shaped bacteria, strains YM11-185 and YM11-159, were isolated from marine sediments in the Republic of Palau. Preliminary analysis based on the 16S rRNA gene sequence revealed that the novel isolates could be affiliated with the family 'Flammeovirgaceae' of the phylum Bacteroidetes. Strains YM1 $1-185^{\top}$ and YM11-159 shared $100 \%$ sequence similarity and showed less than $90 \%$ similarity to cultivated representatives of the family 'Flammeovirgaceae'. The novel isolates are phenotypically and physiologically different from strains described previously. The $G+C$ content of DNA was 27.8-27.9 mol\%, MK-7 was the major menaquinone and iso- $\mathrm{C}_{15: 0}$ and $\mathrm{C}_{16: 1} \omega 7 \mathrm{c}$ were the major fatty acids. On the basis of polyphasic taxonomic studies, it was concluded that strains $\mathrm{YM} 11-185^{\top}$ and $\mathrm{YM} 11-159$ represent a novel species in a new genus of the family 'Flammeovirgaceae', for which the name Limibacter armeniacum gen. nov., sp. nov. is

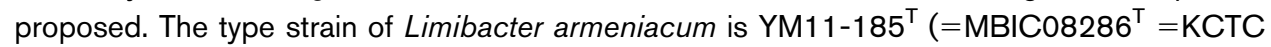
$22132^{\top}$ ).
\end{abstract}

Members of the phylum Bacteroidetes (Ludwig \& Klenk, 2001), also known as the Cytophaga-FlavobacteriumBacteroides group, are ubiquitous in aquatic and marine environments (DeLong et al., 1993; Bowman et al., 1997; Pinhassi et al., 1997; Glöckner et al., 1999; Cottrell \& Kirchman, 2000; O'Sullivan et al., 2002). According to several past reports, they play significant roles as decomposers of organic matter in nature (Cottrell \& Kirchman, 2000; Nedashkovskaya et al., 2003). However, the majority of representatives of the phylum Bacteroidetes remain uncultivated (O'Sullivan et al., 2004). At the time of writing, the family 'Flammeovirgaceae' within the phylum Bacteroidetes incorporates the genera Flammeovirga, Flexithrix, Perexilibacter, Persicobacter, Rapidithrix and Thermonema (Lewin, 1970; Hudson et al., 1989; Nakagawa et al., 1997; Takahashi et al., 2006; Yoon et al., 2007; Srisukchayakul et al., 2007).

Strains YM11-185 ${ }^{\mathrm{T}}$ and YM11-159 were isolated from sediment samples respectively collected from the shore of Carp Island (GPS location $07^{\circ} 05^{\prime} 22.9^{\prime \prime} \mathrm{N} 134^{\circ} 16^{\prime} 46.4^{\prime \prime} \mathrm{E}$ ) and Jellyfish marine lake (GPS location $07^{\circ} 09^{\prime} 41.2^{\prime \prime} \mathrm{N}$ $\left.134^{\circ} 22^{\prime} 30.5^{\prime \prime} \mathrm{E}\right)$ in the Republic of Palau in March 2004.

The GenBank/EMBL/DDBJ accession number for $16 \mathrm{~S}$ rRNA gene sequence of strain $\mathrm{YM} 11-185^{\top}$ is $\mathrm{AB} 359907$.

The composition of medium AnsV is detailed in a supplementary table with the online version of this paper.
Each sample $\left(0.5-1 \mathrm{~cm}^{3}\right)$ was homogenized with a glass rod in $5 \mathrm{ml}$ sterile seawater. A $50 \mu \mathrm{l}$ sample of the homogenate was applied to the surface of AnsV agar medium (the composition of medium AnsV is provided in Supplementary Table S1 in IJSEM Online). Strains YM11$185^{\mathrm{T}}$ and YM11-159 appeared after incubation for 30 days at $25{ }^{\circ} \mathrm{C}$. The apricot- to pale-orange-pigmented colonies were purified on marine 2216 broth (Difco) containing $1.5 \%$ agar after being cultivated for 7-10 days.

In the present study, we attempted to elucidate the phylogenetic position of strains YM1 $1-185^{\mathrm{T}}$ and YM11159 using a polyphasic taxonomic approach including $16 \mathrm{~S}$ rRNA gene sequence analysis, fatty acid composition analysis, quinone analysis and genotypic and physiological comparisons. Based on these data, it is proposed that the isolates represent a novel genus of the family 'Flammeovirgaceae' in the phylum Bacteroidetes.

The temperature and $\mathrm{pH}$ range for growth were determined utilizing 1/10-strength marine 2216 agar (MA; Difco). Salt tolerance was tested on 1/2-strength R2A agar (Difco) containing 0-10\% (w/v) NaCl. Gram-staining was performed as described by Murray et al. (1994). Cell morphology was observed using light microscopy (BX60; Olympus). Gliding motility was determined as described by Perry (1973). Cells of strains YM11-185 ${ }^{\mathrm{T}}$ and YM11-159 were mostly flexible and straight rod-shaped. Cells of both 


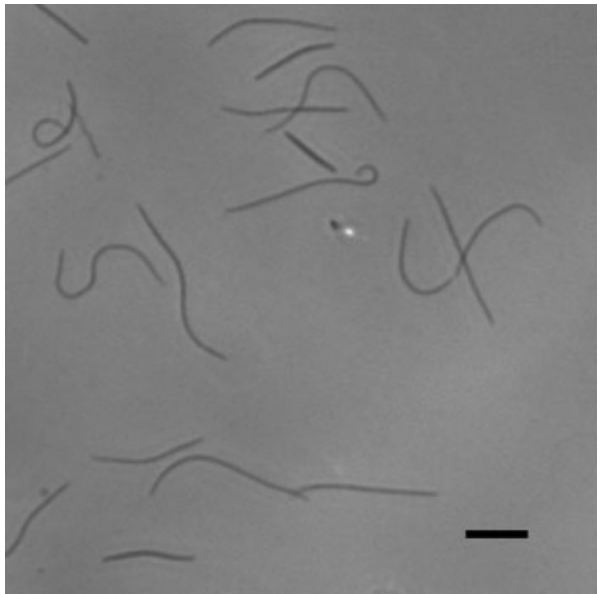

Fig. 1. Phase-contrast micrograph of cells of strain $Y M 11-185^{\top}$. Bar, $10 \mu \mathrm{m}$.

strains were $0.3-0.5 \mu \mathrm{m}$ wide and $15-40 \mu \mathrm{m}$ long (Fig. 1). Gliding motility was observed. Flagella were not seen by electron microscopy. Growth under anaerobic conditions was determined after 2 weeks of incubation in an AnaeroPack (Mitsubishi Gas Chemical Co.) on 1/10strength MA. Catalase activity was determined by bubble formation in a $3 \% \mathrm{H}_{2} \mathrm{O}_{2}$ solution. Oxidase activity was determined by cytochrome oxidase paper (Nissui Pharmaceutical Co.). API 20E, API 50CH and API ZYM strips (bioMérieux) were used to determine physiological and biochemical characteristics. The API 20E and API $50 \mathrm{CH}$ tests were read after $72 \mathrm{~h}$ incubation at $30{ }^{\circ} \mathrm{C}$ and API ZYM tests were read after $4 \mathrm{~h}$ incubation at $37^{\circ} \mathrm{C}$. The substrate oxidation ranges of strains YM11-185 ${ }^{\mathrm{T}}$ and YM11-159 were determined using Biolog MicroPlates. Determination of the respiratory quinone system was carried out as described previously (Xie \& Yokota, 2003). GC analysis of cellular fatty acid methyl esters was performed using a culture grown on 1/10-strength MA at $30{ }^{\circ} \mathrm{C}$ for $48 \mathrm{~h}$ according to the instructions of the Microbial Identification System (MIDI; Microbial ID). DNA was prepared according to the method of Marmur
(1961) from cells grown on 1/10-strength MA and the DNA base composition was determined by using the HPLC method of Mesbah et al. (1989). An approximately $1500 \mathrm{bp}$ fragment of the 16S rRNA gene was amplified from the extracted DNA by using bacterial universal primers $27 \mathrm{~F}$ and 1492R specific to the 16S rRNA gene (Escherichia coli numbering system; Weisburg et al., 1991). To ascertain the phylogenetic position of the new isolates, the 16S rRNA gene sequences of strains YM11-185 ${ }^{\mathrm{T}}$ and YM11-159 were compared with sequences obtained from GenBank (National Center for Biotechnology Information; http:// www.ncbi.nlm.nih.gov). Multiple alignments of the sequences were performed using CLUSTAL_X (version 1.83) (Thompson et al., 1997). Alignment gaps and ambiguous bases were not taken into consideration when 1340 bases of the 16S rRNA gene sequence were compared. Aligned sequences were analysed by the MEGA3.1 software (Kumar et al., 2004). Evolutionary distances [distance options according to the Kimura two-parameter model (Kimura, 1983)] and clustering with the neighbour-joining (Saitou \& Nei, 1987) and maximum-parsimony (Fitch, 1971) methods were determined by using bootstrap values based on 1000 replications (Felsenstein 1985). Similarity values were calculated using the same software.

Comparative analysis of the 16S rRNA gene sequences revealed that strains YM11-185 ${ }^{\mathrm{T}}$ and YM11-159 were affiliated phylogenetically with the family 'Flammeovirgaceae' within the phylum Bacteroidetes with bootstrap confidence value of $100 \%$ in both the neighbour-joining (Fig. 2) and maximum-parsimony (not shown) methods. Analysis of the 16S rRNA gene sequences also indicated that the sequences of strains YM11-185 ${ }^{\mathrm{T}}$ and YM11-159 were identical and that no other sequence showed more than $90 \%$ similarity; related sequences were those of Flammeovirga arenaria NBRC $15982^{\mathrm{T}}$ (84.9\%; Takahashi et al., 2006), Rapidithrix thailandica TISTR $1750^{\mathrm{T}}$ (84.5\%; Srisukchayakul et al., 2007), Perexilibacter aurantiacus MBIC06993 $^{\mathrm{T}}$ (84.4\%; Yoon et al., 2007), Flexithrix dorotheae NBRC $15987^{\mathrm{T}}$ (84.2\%; Lewin, 1970) and Flammeovirga kamogawensis NCIMB $14281^{\mathrm{T}} \quad(84.2 \%$; Hosoya \& Yokota, 2007). All other species of the family 'Flammeovirgaceae' with currently published names were

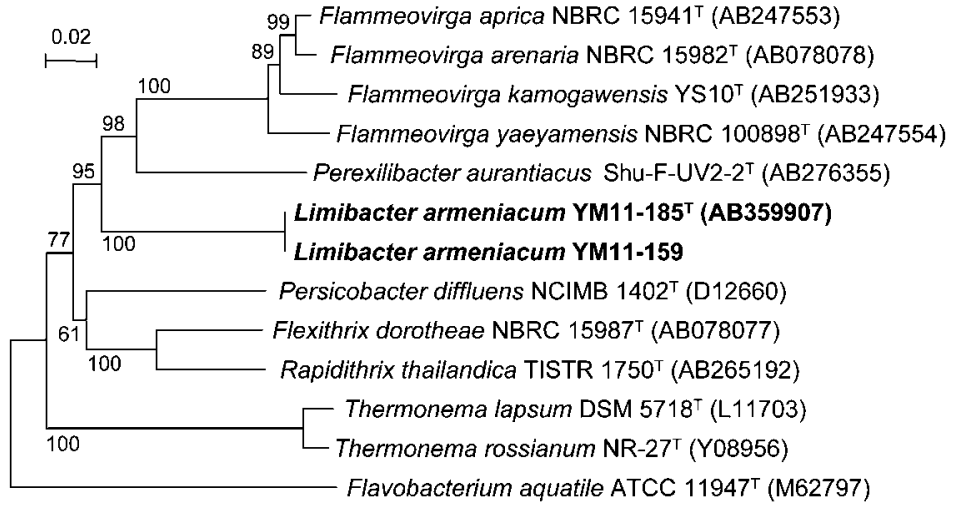

Fig. 2. Neighbour-joining tree based on $16 \mathrm{~S}$ rRNA gene sequence similarity, showing the phylogenetic position of strains YM11-185 and YM11-159 and representatives of closely related and other more distantly related genera of the family 'Flammeovirgaceae'. The tree was rooted using Flavobacterium aquatile ATCC $11947^{\top}$ as the outgroup. Numbers at nodes indicate percentages of occurrence in 1000 bootstrapped trees. Bar, $2 \%$ sequence divergence. 
related more distantly, showing less than $84.0 \% 16 \mathrm{~S}$ rRNA gene sequence similarity. Thus, on the basis of phylogenetic data presented, strains YM11-185 ${ }^{\mathrm{T}}$ and YM11-159 should be classified within a novel genus and species of the family 'Flammeovirgaceae' within the phylum Bacteroidetes.

As shown in Table 1, the predominant cellular fatty acids of strains YM11-185 ${ }^{\mathrm{T}}$ and YM11-159 differentiate them from recognized species of the genera Flammeovirga, Perexilibacter and Rapidithrix based on the proportions of iso- $\mathrm{C}_{15: 0}$ (26.9-28.1\%) and $\mathrm{C}_{16: 1} \omega 7 c(16.8-23.2 \%)$. Furthermore, these strains could also be distinguished from the neighbouring taxa by the presence of $\mathrm{C}_{16: 1} \omega 7 c$ alcohol (2.3-4.2\%) and iso- $\mathrm{C}_{17: 1} \omega 9 c(1.2-1.6 \%)$. Additionally, the two novel isolates showed distinct phenotypic features that distinguished them from the closest described relatives (Table 2).

Based on the results of the phylogenetic analysis and their biochemical and physiological properties, the two novel strains YM11-185 ${ }^{\mathrm{T}}$ and YM11-159 isolated from marine sediments in the Republic of Palau should be considered as members of a novel independent genus and species of the family 'Flammeovirgaceae' within the phylum Bacteroidetes. We propose the name Limibacter armeniacum gen. nov., sp. nov. for these organisms.

\section{Description of Limibacter gen. nov.}

Limibacter [Li.mi.bac'ter. L. adj. limus mud; N.L. masc. n. bacter (equivalent of Gr. neut. n. baktron) rod or staff; N.L.

Table 1. Fatty acid contents of members of the genus Limibacter gen. nov. (strains $\mathrm{YM} 11-185^{\top}$ and $\mathrm{YM} 11-159$ ) and related taxa of the family 'Flammeovirgaceae'

Taxa: 1, strain YM11-185 ${ }^{\mathrm{T}}$; 2, strain YM11-159; 3, Flammeovirga species (data from Takahashi et al., 2006; Hosoya \& Yokota, 2007); 4,

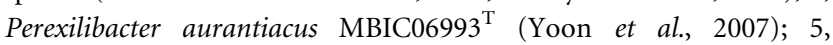
Rapidithrix thailandica TISTR $1750^{\mathrm{T}}$ (Srisukchayakul et al., 2007). Values are percentages of total fatty acid content. -, Not detected; tr, trace.

\begin{tabular}{|lccccc|}
\hline Fatty acid & $\mathbf{1}$ & $\mathbf{2}$ & $\mathbf{3}$ & $\mathbf{4}$ & $\mathbf{5}$ \\
\hline $\mathrm{C}_{13: 1}$ at $12-13$ & 1.6 & 1 & $0.8-2.9$ & 1.6 & - \\
$\mathrm{C}_{14: 0}$ & 1.1 & 1 & $3.7-9$ & 1.9 & 1.2 \\
iso- $_{15: 0}$ & 28.1 & 26.9 & $21.2-54.3$ & 50.6 & 6.3 \\
$\mathrm{C}_{15: 0}$ & 1.7 & $\operatorname{tr}$ & $\operatorname{tr}-7.1$ & 1.4 & $\operatorname{tr}$ \\
$\mathrm{C}_{16: 1} \omega 7 c$ alcohol & 2.3 & 4.2 & - & - & - \\
iso- $_{16: 1} \mathrm{H}$ & 2.2 & 3.1 & $\operatorname{tr}-3.2$ & - & - \\
$\mathrm{C}_{16: 0} \mathrm{~N}$ alcohol & 3.2 & 10 & $\operatorname{tr}-1.8$ & - & - \\
$\mathrm{C}_{16: 1} \omega 7 c$ & 23.2 & 16.8 & - & 16.7 & 1.5 \\
$\mathrm{C}_{16: 1} \omega 5 c$ & 9.9 & 7.9 & $1.8-4.7$ & 4.9 & 44.8 \\
$\mathrm{C}_{16: 0}$ & 3.5 & 4.4 & $2.8-4.8$ & 3.76 & 4 \\
iso- $_{15: 0} 3-\mathrm{OH}$ & 3.7 & 2.4 & $3.9-5.5$ & 2.2 & 4.3 \\
iso- $_{17: 1} \omega 9 c$ & 1.6 & 1.2 & - & - & - \\
$\mathrm{C}_{17: 1} \omega 6 c$ & 1 & $\operatorname{tr}$ & - & $\operatorname{tr}$ & - \\
$\mathrm{C}_{16: 0} 3-\mathrm{OH}$ & 4.9 & 2.8 & $4.1-14.6$ & 2.2 & 3.8 \\
iso- $\mathrm{C}_{17: 0} 3-\mathrm{OH}$ & 4.5 & 3.5 & $2-2.4$ & 2.4 & 10.8 \\
\hline
\end{tabular}

masc. n. Limibacter rod from mud, referring to the isolation source of the first strains].

Cells are rod-shaped, Gram-negative and strictly aerobic. Motile by gliding. Do not form endospores. Catalase- and oxidase-positive. Nitrate and nitrite are not reduced. The major respiratory menaquinone is $\mathrm{MK}-7$. The $\mathrm{G}+\mathrm{C}$ content of the genomic DNA of the type strain of the type species is $27.9 \mathrm{~mol} \%$. Predominant cellular fatty acids are iso- $\mathrm{C}_{15: 0}$ and $\mathrm{C}_{16: 1} \omega 7 c$. The type species is Limibacter armeniacum.

\section{Description of Limibacter armeniacum sp. nov.}

Limibacter armeniacum [ar.me' ni.a.cum. L. neut. n. armeniacum (nominative in apposition) an apricot, a rod called the apricot, intended to mean apricot-coloured].

Main characteristics are the same as those given for the genus. In addition, cells are long rods, $0.3-0.5 \mu \mathrm{m}$ wide and 15-40 $\mu \mathrm{m}$ long. Colonies grown on 1/10-strength MA are circular, convex and apricot- to pale-orange-pigmented. The temperature range for growth is $17-37{ }^{\circ} \mathrm{C}$; optimal growth occurs at $27-30{ }^{\circ} \mathrm{C}$ and no growth occurs at 4 or $45{ }^{\circ} \mathrm{C}$. The $\mathrm{pH}$ range for growth is $7-9$, with an optimum around neutral $\mathrm{pH}$. $\mathrm{NaCl}$ is required for growth and can be tolerated up to $6.5 \%(\mathrm{w} / \mathrm{v})$. Seawater is not required for growth. Gelatin is hydrolysed but agar and starch are not. Positive for $o$-nitrophenyl $\beta$-D-galactosidase (ONPG) and production of tryptophan deaminase. Negative for the Voges-Proskauer reaction, citrate utilization and production of arginine dihydrolase, lysine decarboxylase, ornithine decarboxylase, hydrogen sulfide and indole. Acid is produced from galactose, glucose, aesculin ferric citrate, melibiose, sucrose, trehalose, turanose, D-lyxose, Dtagatose and 5-ketogluconate, but not from $\mathrm{D}^{-}$or L-arabinose, ribose, D- or L-xylose, methyl $\beta$-D-xylopyranoside, fructose, mannose, rhamnose, methyl $\alpha$-D-mannopyranoside, methyl $\alpha$-D-glucopyranoside, $N$-acetylglucosamine, amygdalin, arbutin, salicin, cellobiose, maltose, lactose, melezitose, inulin, raffinose, gentiobiose, $\mathrm{D}$ - or Lfucose, glycerol, erythritol, adonitol, sorbose, dulcitol, inositol, mannitol, sorbitol, starch, glycogen, xylitol, Dor L-arabitol, gluconate or 2-ketogluconate. Alkaline phosphatase, leucine arylamidase, valine arylamidase, acid phosphatase, naphthol-AS-BI-phosphohydrolase and $N$ acetyl- $\beta$-glucosaminidase tests are positive, but esterase (C4), esterase lipase (C8), lipase (C4), cystine arylamidase, trypsin, chymotrypsin, $\alpha$-galactosidase, $\beta$-galactosidase, $\beta$ glucuronidase, $\alpha$-glucosidase, $\beta$-glucosidase, $\alpha$-mannosidase and $\alpha$-fucosidase tests are negative. Cyclodextrin, dextrin, glycogen, $N$-acetyl-D-glucosamine, L-arabinose, cellobiose, D-galactose, gentiobiose, maltose, D-lactose, Dmannose and trehalose are oxidized, but D-fructose, Lfucose, D-glucose, D-mannitol, melibiose, D-sorbitol, acetic acid, cis-aconitic acid, $\alpha$-ketobutyric acid, $\alpha$-ketoglutaric acid, inosine, glucose 1-phosphate, Tween 40, Tween 80, $N$-acetyl-D-galactosamine, adonitol, D-arabitol, i-erythritol, myo-inositol, lactulose, methyl $\beta$-D-glucoside, D-psicose, 
Table 2. Characteristics that differentiate members of the genus Limibacter gen. nov. (strains $\mathrm{YM} 11-185^{\top}$ and $\mathrm{YM} 11-159$ ) from related taxa of the family 'Flammeovirgaceae'

Taxa: 1, strain YM11-185 ${ }^{\mathrm{T}}$; 2, strain YM11-159; 3, Flammeovirga aprica NBRC $15941^{\mathrm{T}}$ (data from Takahashi et al., 2006); 4, Flammeovirga arenaria NBRC $15982^{\mathrm{T}}$ (Takahashi et al., 2006); 5, Flammeovirga yaeyamensis NBRC $100898^{\mathrm{T}}$ (Takahashi et al., 2006); 6, Flammeovirga kamogawensis NCIMB $14281^{\mathrm{T}}$ (Hosoya \& Yokota, 2007); 7, Perexilibacter aurantiacus MBIC06993 ${ }^{\mathrm{T}}$ (Yoon et al., 2007); 8, Rapidithrix thailandica TISTR 1750 ${ }^{\mathrm{T}}$ (Srisukchayakul et al., 2007); 9, Flexithrix dorotheae ATCC $23163^{\mathrm{T}}$ (Lewin, 1970); 10, Persicobacter diffluens (Nakagawa et al., 1997). +, Positive; w, weakly positive; $v$, variable; -, negative; ND, no data.

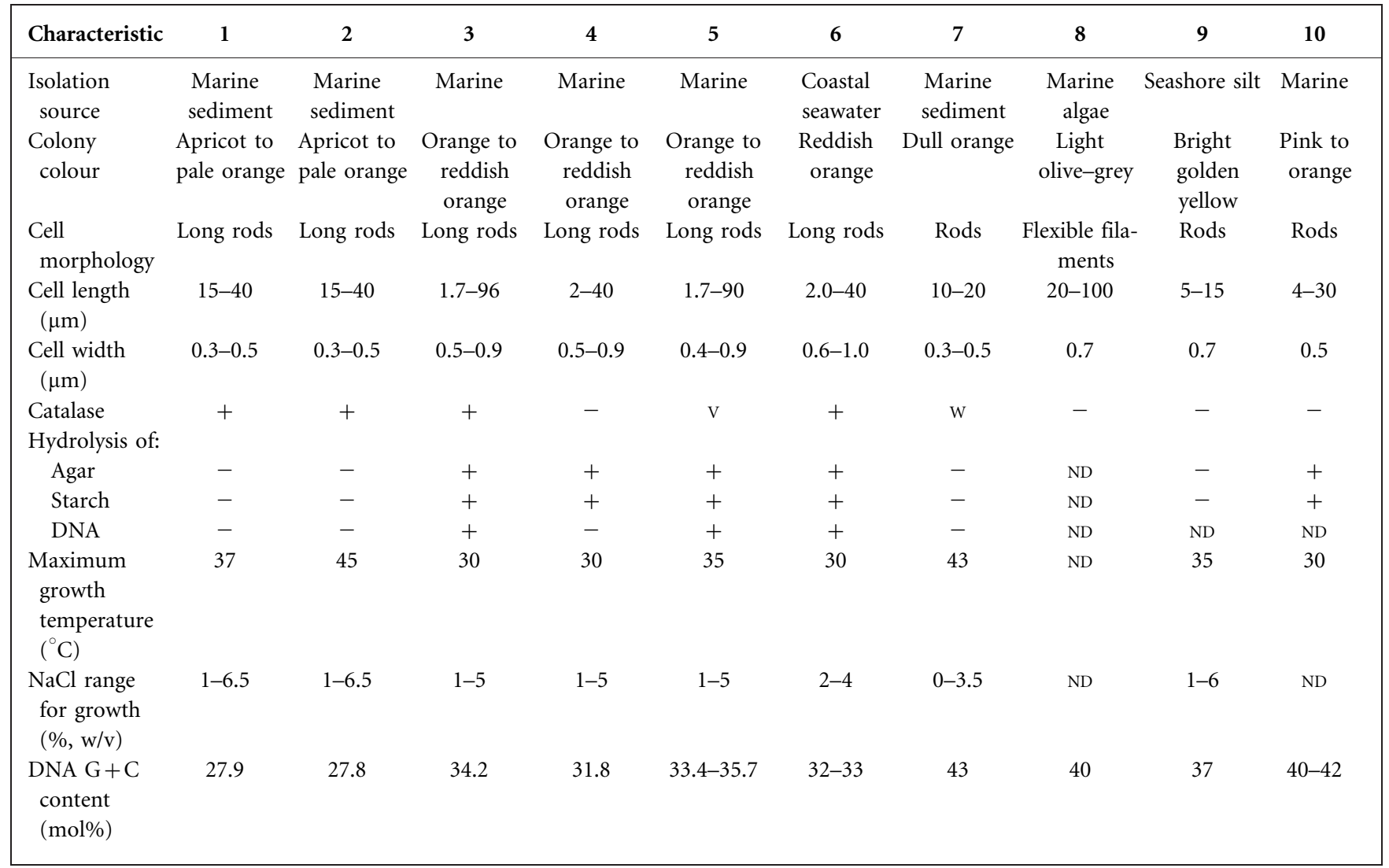

raffinose, L-rhamnose, sucrose, furanose, xylitol, methyl pyruvate, monomethyl succinate, citric acid, formic acid, D-galactonic acid lactone, D-galacturonic acid, D-gluconic acid, D-glucosaminic acid, D-glucuronic acid, $\alpha-, \beta$ - and $\gamma$ hydroxybutyric acids, $p$-hydroxyphenylacetic acid, itaconic acid, $\alpha$-ketovaleric acid, DL-lactic acid, malonic acid, propionic acid, quinic acid, D-saccharic acid, sebacic acid, succinic acid, bromosuccinic acid, succinamic acid, glucuronamide, alaninamide, D- and L-alanine, L-alanyl glycine, L-asparagine, L-aspartic acid, L-glutamic acid, glycyl L-aspartic acid, glycyl L-glutamic acid, L-histidine, hydroxy-L-proline, L-leucine, L-ornithine, L-phenylalanine, L-proline, L-pyroglutamic acid, D- and L-serine, L-threonine, DL-carnitine, $\gamma$-aminobutyric acid, urocanic acid, uridine, thymidine, phenylethylamine, putrescine, 2-aminoethanol, 2,3-butanediol, glycerol, DL- $\alpha$-glycerol phosphate and D-glucose 6-phosphate are not oxidized. Major fatty acid components $(>1.0 \%)$ include $\mathrm{C}_{13: 1}$ at $12-13$ $(1.6 \%), \mathrm{C}_{14: 0}(1.1 \%)$, iso- $\mathrm{C}_{15: 0}(28.1 \%), \mathrm{C}_{15: 0}(1.7 \%)$, $\mathrm{C}_{16: 1} \omega 7 c$ alcohol $(2.3 \%)$, iso- $\mathrm{C}_{16: 1} \mathrm{H}(2.2 \%), \mathrm{C}_{16: 0} \mathrm{~N}$ alcohol (3.2\%), $\mathrm{C}_{16: 1} \omega 7 c(23.2 \%), \mathrm{C}_{16: 1} \omega 5 c \quad(9.9 \%)$, $\mathrm{C}_{16: 0} \quad(3.5 \%)$, iso- $\mathrm{C}_{15: 0} \quad 3-\mathrm{OH} \quad(3.7 \%)$, iso- $\mathrm{C}_{17: 1} \omega 9 c$ $(1.6 \%), \mathrm{C}_{17: 1} \omega 6 c(1.0 \%), \mathrm{C}_{16: 0} 3-\mathrm{OH}(4.9 \%)$ and iso$\mathrm{C}_{17: 0} 3-\mathrm{OH}(4.5 \%)$.

The type strain is YM11-185 ${ }^{\mathrm{T}}\left(=\mathrm{MBIC} 08286^{\mathrm{T}}=\mathrm{KCTC}\right.$ $22132^{\mathrm{T}}$ ), which was isolated from sediment samples collected from the shore of Carp Island, Republic of Palau.

\section{Acknowledgements}

The authors are grateful to Atsuko Katsuta, Ayako Matsuzaki, Tomomi Haga and Yukiko Itazawa for their technical assistance. This work was supported by the New Energy and Industrial Technology Development Organization (NEDO).

\section{References}

Bowman, J. P., McCammon, S. A., Brown, M. V., Nichols, D. S. \& McMeekin, T. A. (1997). Diversity and association of psychrophilic bacteria in Antarctic sea ice. Appl Environ Microbiol 63, 3068-3078. 
Cottrell, M. T. \& Kirchman, D. L. (2000). Community composition of marine bacterioplankton determined by $16 \mathrm{~S}$ rRNA gene clone libraries and fluorescence in situ hybridization. Appl Environ Microbiol 66, 5116-5122.

DeLong, E. F., Franks, D. G. \& Alldredge, A. L. (1993). Phylogenetic diversity of aggregate-attached vs. free-living marine bacterial assemblages. Limnol Oceanogr 38, 924-934.

Felsenstein, J. (1985). Confidence limits on phylogenies: an approach using the bootstrap. Evolution 39, 783-791.

Fitch, W. M. (1971). Toward defining the course of evolution: minimum change for a specific tree topology. Syst Zool 20, 406-416.

Glöckner, F. O., Fuchs, B. M. \& Amann, R. (1999). Bacterioplankton composition of lakes and oceans: a first comparison based on fluorescence in situ hybridization. Appl Environ Microbiol 65, 3721-3726.

Hosoya, S. \& Yokota, A. (2007). Flammeovirga kamogawensis sp. nov., isolated from coastal seawater in Japan. Int J Syst Evol Microbiol 57, 1327-1330.

Hudson, J. A., Schofield, K. M., Morgan, H. W. \& Daniel, R. M. (1989), Thermonema lapsum gen. nov., sp. nov., a thermophilic gliding bacteria. Int J Syst Bacteriol 39, 485-487.

Kimura, M. (1983). The Neutral Theory of Molecular Evolution. Cambridge: Cambridge University Press.

Kumar, S., Tamura, K. \& Nei, M. (2004). MEGA3: integrated software for molecular evolutionary genetics analysis and sequence alignment. Brief Bioinform 5, 150-163.

Lewin, R. A. (1970). Flexithrix dorotheae gen. et sp. nov. (Flexibacterales); and suggestions for reclassifying sheathed bacteria. Can J Microbiol 16, 511-515.

Ludwig, W. \& Klenk, H.-P. (2001). Overview: a phylogenetic backbone and taxonomic framework for prokaryotic systematics. In Bergey's Manual of Systematic Bacteriology, 2nd edn, vol. 1, pp. 49-65. Edited by D. R. Boone, R. W. Castenholz \& G. M. Garrity. New York: Springer.

Marmur, J. (1961). A procedure for the isolation of deoxyribonucleic acid from micro-organisms. J Mol Biol 3, 208-218.

Mesbah, M., Premachandran, U. \& Whitman, W. B. (1989). Precise measurement of the $\mathrm{G}+\mathrm{C}$ content of deoxyribonucleic acid by highperformance liquid chromatography. Int J Syst Bacteriol 39, 159-167.

Murray, R. G. E., Doetsch, R. N. \& Robinow, C. F. (1994), Determinative and cytological light microscopy. In Methods for General and Molecular Bacteriology, pp. 21-41. Edited by P. Gerhardt, R. G. E. Murray, W. A. Wood \& N. R. Krieg. Washington, DC: American Society for Microbiology.

Nakagawa, Y., Hamana, K., Sakane, T. \& Yamasato, K. (1997) Reclassification of Cytophaga aprica (Lewin 1969) Reichenbach 1989 in Flammeovirga gen. nov. as Flammeovirga aprica comb. nov. and of
Cytophaga diffluens (ex Stanier 1940; emend. Lewin 1969) Reichenbach 1989 in Persicobacter gen. nov. as Persicobacter diffluens comb. nov. Int J Syst Bacteriol 47, 220-223.

Nedashkovskaya, O. I., Suzuki, M., Vysotskii, M. V. \& Mikhailov, V. V. (2003). Reichenbachia agariperforans gen. nov., sp. nov., a novel marine bacterium in the phylum Cytophaga-FlavobacteriumBacteroides. Int J Syst Evol Microbiol 53, 81-85.

O’Sullivan, L. A., Weightman, A. J. \& Fry, J. C. (2002). New degenerate Cytophaga-Flexibacter-Bacteroides-specific 16S ribosomal DNA-targeted oligonucleotide probes reveal high bacterial diversity in River Taff epilithon. Appl Environ Microbiol 68, 201-210.

O’Sullivan, L. A., Fuller, K. E., Thomas, E. M., Turley, C. M., Fry, J. C. \& Weightman, A. J. (2004). Distribution and culturability of the uncultivated 'AGG58 cluster' of the Bacteroidetes phylum in aquatic environments. FEMS Microbiol Ecol 47, 359-370.

Perry, L. B. (1973). Gliding motility in some non-spreading flexibacteria. J Appl Bacteriol 36, 227-232.

Pinhassi, J., Zweifel, U. L. \& Hagström, Å. (1997). Dominant marine bacterioplankton species found among colony-forming bacteria. Appl Environ Microbiol 63, 3359-3366.

Saitou, N. \& Nei, M. (1987). The neighbor-joining method: a new method for reconstructing phylogenetic trees. Mol Biol Evol 4, 406-425.

Srisukchayakul, P., Suwanachart, C., Sangnoi, Y., Kanjana-Opas, A., Hosoya, S., Yokota, A. \& Arunpairojana, V. (2007). Rapidithrix thailandica gen. nov., sp. nov., a marine gliding bacteria isolated from the Andaman sea, along the southern coastline of Thailand. Int J Syst Evol Microbiol 57, 2275-2279.

Takahashi, M., Susuki, K. \& Nakagawa, Y. (2006). Emendation of the genus Flammeovirga and Flammeovirga aprica with the proposal of Flammeovirga arenaria nom. rev., comb. nov. and Flammeovirga yaeyamensis sp. nov. Int J Syst Evol Microbiol 56, 2095-2100.

Thompson, J. D., Gibson, T. J., Plewniak, F., Jeanmougin, F. \& Higgins, D. G. (1997). The CLUSTAL_X windows interface: flexible strategies for multiple sequence alignment aided by quality analysis tools. Nucleic Acids Res 25, 4876-4882.

Weisburg, W. G., Barns, S. M., Pelletier, D. A. \& Lane, D. J. (1991). $16 \mathrm{~S}$ ribosomal DNA amplification for phylogenetic study. J Bacteriol 173 , 697-703.

Xie, C.-H. \& Yokota, A. (2003). Phylogenetic analyses of Lampropedia hyalina based on the 16S rRNA gene sequence. J Gen Appl Microbiol 49, 345-349.

Yoon, J., Ishikawa, S., Kasai, H. \& Yokota, A. (2007). Perexilibacter aurantiacus gen. nov., sp. nov., a novel member of the family 'Flammeovirgaceae' isolated from sediment. Int J Syst Evol Microbiol 57, 964-968. 